\title{
The effect of Beverages on Color Stability of Highly Impact Acrylic Resin
}

Ammar Kh. Al-Noori BDS, MSc,PhD(Asst. Prof)
Department of Prosthodontics

College of Dentistry, University of Mosul

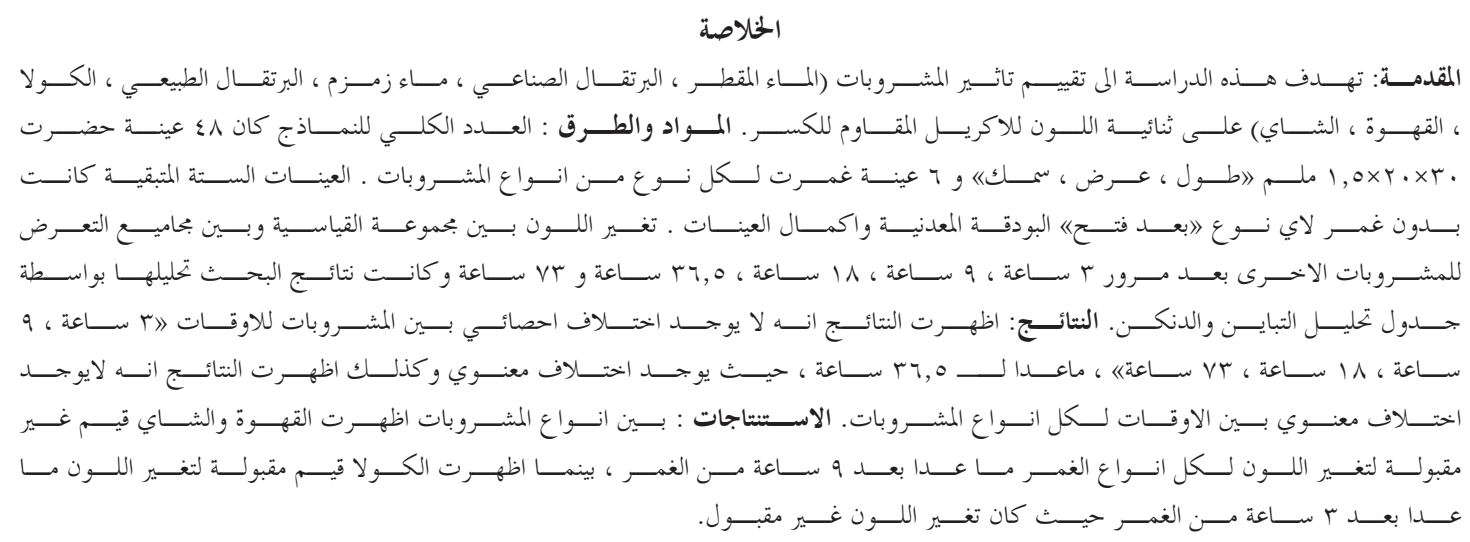

\section{ABSTRACT}

Aim: To evaluate the effect of beverages (Distilled water ,Artificial orange, Zamzam water, Natural orange, Cola, coffee, and Tea) on the color stability of the highly impact resin. Materials and methods: Total samples of this research were (48) samples of highly impact resin were prepared $30 * 20 * 1.5 \mathrm{~mm}$ (length, width and thickness). Six samples were immersed in each type of beverage. The last six sample (control) without any type of beverage (after control group and other beverage groups were evaluated after ( 3 hours, 9 hrs, 18 hrs, 36.5 hrs, and $73 \mathrm{hrs}$ ) immersion time intervals by using (CIE L* a* b*) system. the results of this research were analyzed statistically by ANOVA and Duncan's multiple range test. Results : There was no significant difference among beverages at immersion time intervals ( $3 \mathrm{hrs,}$ $9 \mathrm{hrs}, 18 \mathrm{hrs}$, and $73 \mathrm{hrs}$ ) except at ( $36.5 \mathrm{hrs})$ there was a significant difference, also the results showed that there was no significant difference among immersion time intervals for different types of bever-ages. Conclusions: among beverages coffee and tea showed unaccepted value of $\Delta \mathrm{E}$ at all immersion time intervals except at $(9 \mathrm{hrs})$ while cola showed an accepted values of $\Delta \mathrm{E}$ except at ( $3 \mathrm{hrs})$ of immer-sion where $\Delta \mathrm{E}$ value was unaccepted.

Key words: Color stability, Beverage, Highly impact resin.

The effect of beverages on color stability of highly impact acrylic resin. Al-Rafidain Dent J.; Al-Rafidain Dent J. 2015; 15(1): 329-339.

Received: $12 / 8 / 2012 \quad$ Sent to Referees: $27 / 8 / 2012$

Accepted for Publication: 25/9/2012

\section{INTRODUCTION}

Acrylic resin has been introduced in 1937 for construction complete and partial dentures, and had been widely used due to their acceptable esthetic, low permeability in oral fluid and color stability ${ }^{(1,2,3)}$.

Color was an important property for esthetic evaluation of acrylic resin denture base after exposure to beverages and food ${ }^{(4)}$.

One type of highly impact acrylic resin was prepared by adding the elastomer, to polymethyle methacrylate which act as a plastifying agent, the addition of elastomers to the material increase the ability of absorb energy and over come the possibility of resin fracture $^{(5,6)}$

Color change of prosthodontic materials might result in patient dissatisfaction and increase the possibility of prosthesis replacement ${ }^{(7)}$.

Studies demonstrated that coffee, cola, and juice deposite stains on dental materials and resulted in a gloss changes ${ }^{(8,9)}$. Increased experimental time period showed a decrease in the gloss of denture acrylic resin ${ }^{(10)}$.

Imirzalioglu et al ${ }^{(11)}$ found that the color shifts of heat polymerized acrylic, injection molded acrylic, and autopolymerized acrylic were clinically acceptable $(\Delta \mathrm{E}<3.7)$ after 30 days of soaking in tea, coffee and nicotine.

Navarro et al ${ }^{(12)}$ showed that the staining effect of coffee of two heat cured denture base acrylic (Lucitone 550, Vipicril), and one nylon denture base resin (Transflex) to

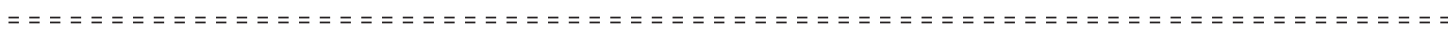


be at a clinically acceptable levels after 30 days of immersion.

The present research was designed to evaluate the effect of beverages (Distilled water ,Artificial orange, Zamzam water, Natural orange, Cola, Coffee, and tea) on color stability of highly impact acrylic resin. Also, to evaluate the effect of immersion time on color stability of highly impact acrylic resin.

\section{MATERIALS AND METHODS}

In this research, the used beverages were Distilled water, Artificial juice (Rani orange. Aujan Industries co.,Kindom of Saudi Arabia), zamam water, natural orange juice, cola, coffee, and tea. $30 \mathrm{gm}$ of tea
(Alghazaleen) and $30 \mathrm{gm}$ of coffee powder (Brazilian coffee) were added into one liter of boiling distilled water, then simmered for 5 minute and filtered through filter paper ${ }^{(13,14)}$.

Highly impact acrylic (VertexTMNetherland) was polymerized in water bath at $70^{\circ} \mathrm{C}$ for 90 minute and raised to $100^{\circ} \mathrm{Cfor} 30$ minute according to manufacturers instruction. After deflasking, the samples were abraded on both sides with (600) grit sand paper. A slurry of water and pumice were applied for polishing ${ }^{(12)}$.

The $\mathrm{pH}$ values of beverages were measured by using $\mathrm{pH}$ meter device. After cleaning the electrode and calibrating the device, then the $\mathrm{pH}$ values of beverages were measured as shown in Table (1).

Table (1) : pH Values of Beverages

\begin{tabular}{cc}
\hline Beverage & pH \\
\hline Artificial orange & 2.66 \\
Distilled water & 70 \\
Zamzam & 7.92 \\
Natural orange & 2.64 \\
Cola & 1.84 \\
Coffee & 5.24 \\
Tea & 5.71 \\
\hline
\end{tabular}

Forty eight samples of acrylic were prepared with dimensions of $30 * 20 * 1.5$ mm (length, width, and thickness) ${ }^{(14,15)}$. six samples were immersed for each type of beverages, the remain six sample being evaluated as a control (after deflasking, finishing, and polishing) with out immersion in beverage.

The samples were converted to digital images by using digital scanner (HP scanner, HP desk jet F 2280). The images were digitized with an input resolution of 1200 pixels per inch ${ }^{(16)}$. These digital images were prepared with dimension 85 pixels X85 pixels for each sample by soft were program Adob photoshop 9.0, then these images were saved. Special program were used, operating with in MATLAB to reach direct values of (CIE $\mathrm{L}^{*} \mathrm{a}^{*} \mathrm{~b}$ ) for (7225) pixels that were presented in these surface area of image ${ }^{(17)}$. Each (CIE L*a*b*) for all pixels will be given values, and the result present directly on excel program. The total color change $\Delta \mathrm{E}$ of each sample was calculated using the following formula ${ }^{(18,19)}$

$\Delta \mathrm{E}=\left[\left(\Delta \mathrm{L}^{*}\right) 2+\left(\Delta \mathrm{a}^{*}\right) 2+\left(\Delta \mathrm{L}^{*}\right) 2\right] 1 / 2$

$\Delta \mathrm{E}=[(\mathrm{L} 2 *-\mathrm{L} 1 *) 2+(\mathrm{a} 2 *-\mathrm{a} 1 *) 2+(\mathrm{L} 2 *-\mathrm{L} 1 *) 2] 1 / 2$
When no color difference will be detected after its exposure to the testing environment $(\Delta \mathrm{E}=\mathrm{O}) . \Delta \mathrm{E}$ value of 3.7 or less was considered to be clinically acceptable in vitro study ${ }^{(19)}$

The protocol of immersion time was as a continues immersion ${ }^{(20)}$ and was estimated in this research as follows : 3 caps of liquid per day time, 2 minute of each cup through 365 days $(3 \times 2 \times 365)$ equal to 2190 min (36.5 hours per year) so, the immersion time intervals were $3,9,18,36.5$ and 73 hours represent $1,3,6,12$, and 24 months respectively.

The following statistical methods were used to analyze and assess the results with SPSS V 11.5 for windows, descriptive statistics include mean \pm standard deviation values, ANOVA and Duncan multiple range test were used. The statistical results were considered significant at $\mathrm{P} \leq 0.05$.

\section{RESULTS}

In this research, the scanner image was used because it could be used to digitally evaluate color change of dental materials with (CIE L*a*b*) system $^{(15,16)}$.

Color change $(\Delta \mathrm{E})$ measurements of 
highly impact resin in comparison among beverages (Figures 1-5) demonstrated the mean \pm standard deviation values and Duncan's multiple range test of color change $\Delta \mathrm{E}$.

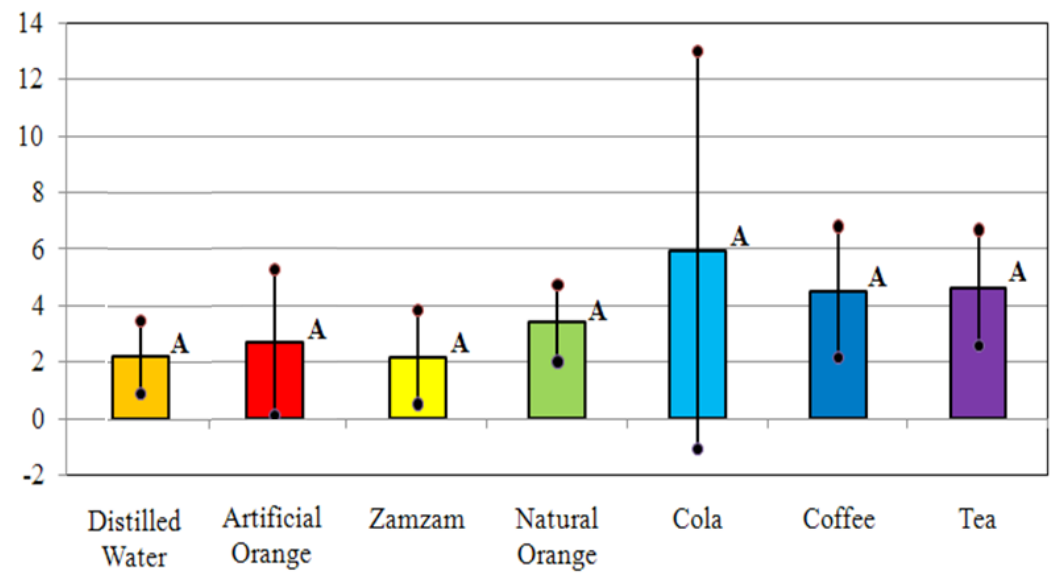

3 Hour

Figure (1) : Mean $\pm \mathrm{SD}$ and Duncan's multiple range test of color change $\Delta \mathrm{E}$ for comparison among beverages at $3 \mathrm{hrs}$ of immersion

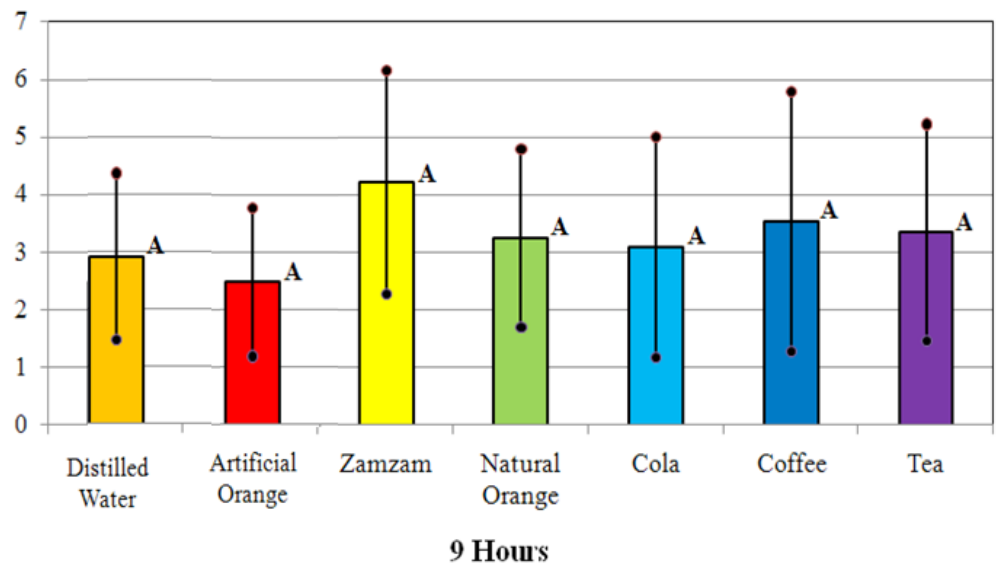

Figure (2) : Mean $\pm \mathrm{SD}$ and Duncan's multiple range test of color change $\Delta \mathrm{E}$ for comparison among beverages at $9 \mathrm{hrs}$ of immersion

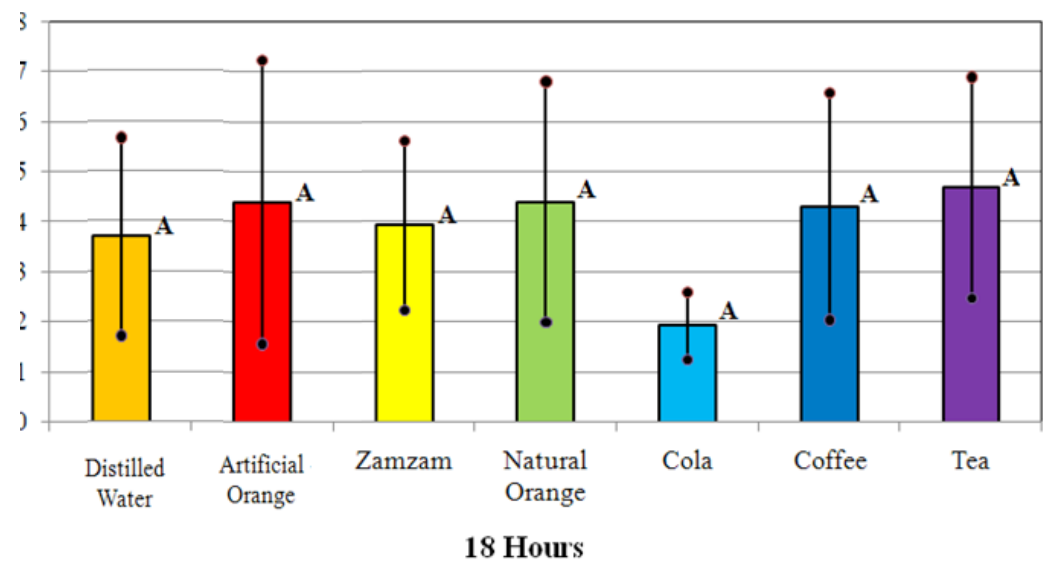

Figure (3) : Mean $\pm \mathrm{SD}$ and Duncan's multiple range test of color change $\Delta \mathrm{E}$ for comparison among beverages at $18 \mathrm{hrs}$ of immersion 


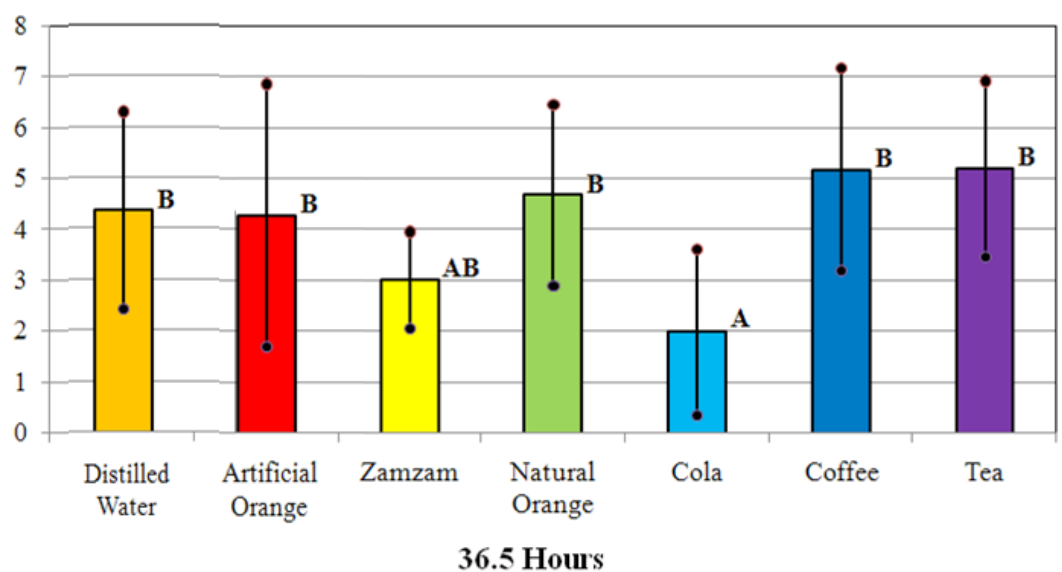

Figure (4) : Mean $\pm \mathrm{SD}$ and Duncan's multiple range test of color change $\Delta \mathrm{E}$ for comparison among bever-ages at $36.5 \mathrm{hrs}$ of immersion

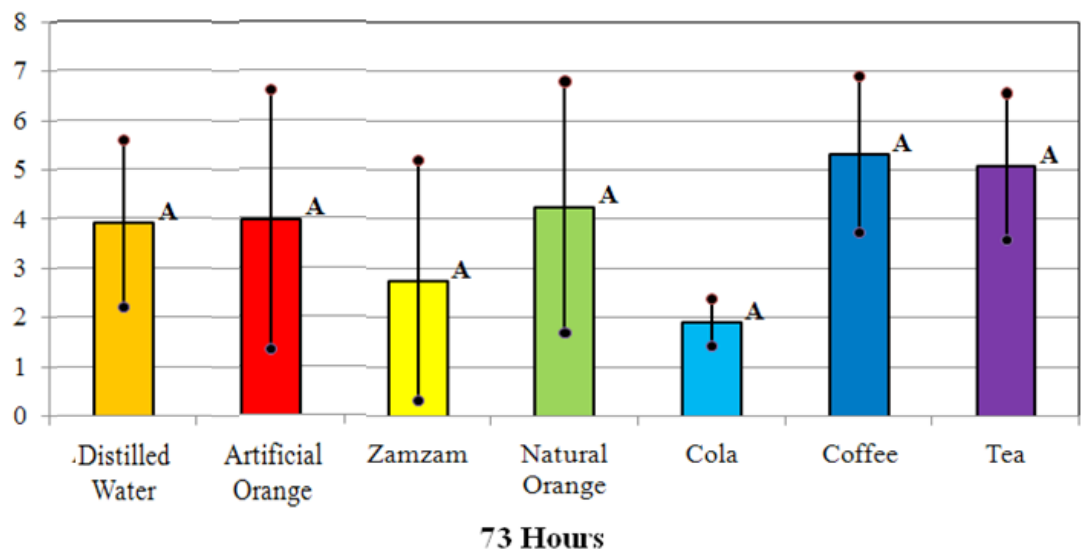

Figure (5) : Mean $\pm \mathrm{SD}$ and Duncan's multiple range test of color change $\Delta \mathrm{E}$ for comparison among bever-ages at $73 \mathrm{hrs}$ of immersion

The one way analysis of variance (ANOVA) as shown in (Table 2) demonstrated that there was no significant differences among beverages at immersion time intervals $(3 \mathrm{hrs}, 9 \mathrm{hrs}, 18 \mathrm{hrs}$, and $73 \mathrm{hrs})$ except at ( $36.5 \mathrm{hrs})$ there was a significant difference among beverages where the lowest color change, showed with cola that significantly not differ from Zamzam water (Figure 4). 
Table (2) : Analysis of variance (ANOVA) for comparison of color change $\Delta \mathrm{E}$ among different types of beverage

\begin{tabular}{|c|c|c|c|c|c|c|}
\hline Time & SOV & SS & df & MS & F-value & p-value \\
\hline \multirow{3}{*}{$3 \mathrm{Hr}$} & Between Groups & 73.589 & 6 & 12.265 & \multirow{3}{*}{1.193} & \multirow{3}{*}{0.333} \\
\hline & Within Groups & 359.961 & 35 & 10.285 & & \\
\hline & Total & 433.550 & 41 & & & \\
\hline \multirow{3}{*}{9 Hrs } & Between Groups & 10.469 & 6 & 1.745 & \multirow{3}{*}{0.551} & \multirow{3}{*}{0.766} \\
\hline & Within Groups & 110.891 & 35 & 3.168 & & \\
\hline & Total & 121.360 & 41 & & & \\
\hline \multirow{3}{*}{$18 \mathrm{Hrs}$} & Between Groups & 31.336 & 6 & 5.223 & \multirow{3}{*}{1.174} & \multirow{3}{*}{0.342} \\
\hline & Within Groups & 155.718 & 35 & 4.449 & & \\
\hline & Total & 187.054 & 41 & & & \\
\hline \multirow{3}{*}{ 36.5 Hrs } & Between Groups & 50.309 & 6 & 8.385 & \multirow{3}{*}{2.451} & \multirow{3}{*}{$0.044^{*}$} \\
\hline & Within Groups & 119.758 & 35 & 3.422 & & \\
\hline & Total & 170.067 & 41 & & & \\
\hline \multirow{3}{*}{$73 \mathrm{Hrs}$} & Between Groups & 52.821 & 6 & 8.804 & \multirow{3}{*}{2.266} & \multirow{3}{*}{0.059} \\
\hline & Within Groups & 135.979 & 35 & 3.885 & & \\
\hline & & 188.800 & 41 & & & \\
\hline
\end{tabular}

SOV: Source of variance; SS: Sum of squares; MS: Mean square; df: Degree of freedom.

* indicated significant difference at $\mathrm{p}<0.05$.

The explanation of this results might due to low $\mathrm{pH}$ of cola $(\mathrm{pH}-1.84)$ that cause solubility of the resin and later, absorption might take place with increasing immersion time. The very high acidity of the solution leads to an increase in water sorption $^{(21)}$. The equilibrium between solubility and absorption processes resulting in decreasing the color change ${ }^{(13)}$. Zamzam water was alkaline $(\mathrm{pH}=7.92)$ and characterized by the presence of metals, cations and anions ${ }^{(22)}$, resulting in a difference in color change from that of distilled water $(\mathrm{pH}=7.0)$.

Color change $(\Delta \mathrm{E})$ measurements of highly impact resin in comparison among immersion time intervals (Figures 6-12) demonstrated the mean \pm standard deviation values and Duncan's multiple range test of color change $(\Delta \mathrm{E})$.

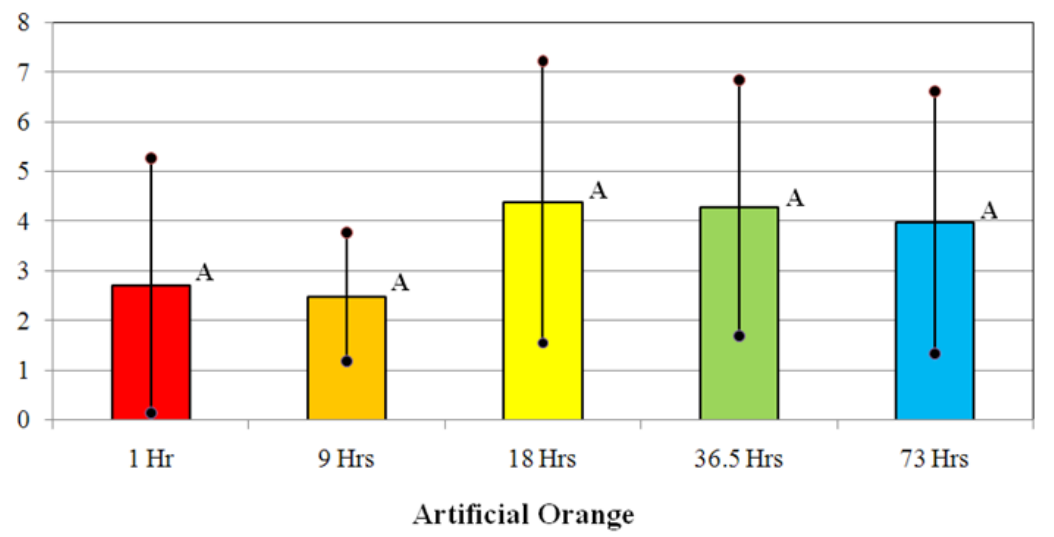

Figure (6) : Mean $\pm \mathrm{SD}$ and Duncan's multiple range test of color change $\Delta \mathrm{E}$ for comparison among immer-sion time intervals for artificial orange 


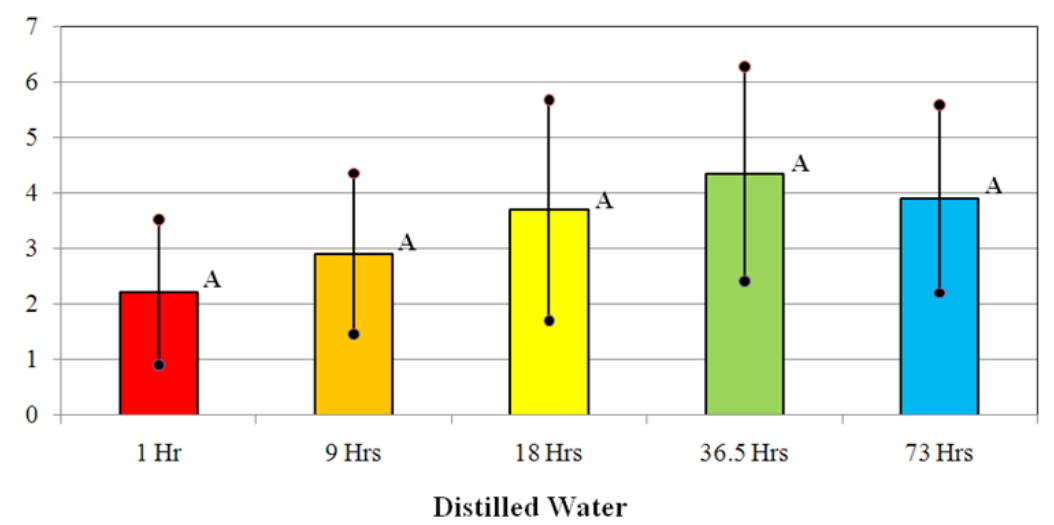

Figure (7) : Mean $\pm \mathrm{SD}$ and Duncan's multiple range test of color change $\Delta \mathrm{E}$ for comparison among immer-sion time intervals for distilled water

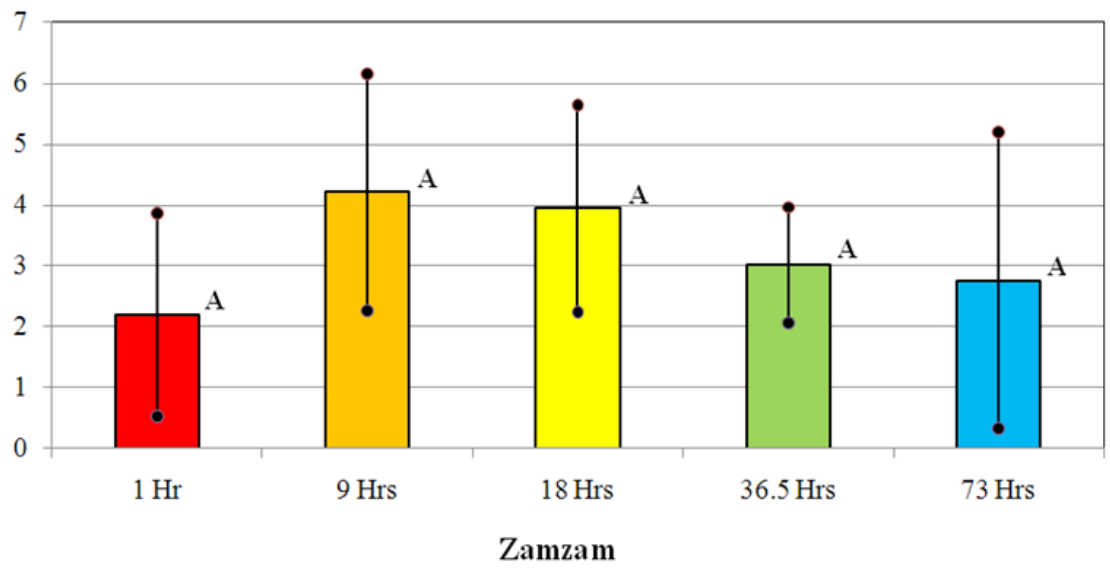

Figure (8) : Mean $\pm \mathrm{SD}$ and Duncan's multiple range test of color change $\Delta \mathrm{E}$ for comparison among immer-sion time intervals for zamzam water

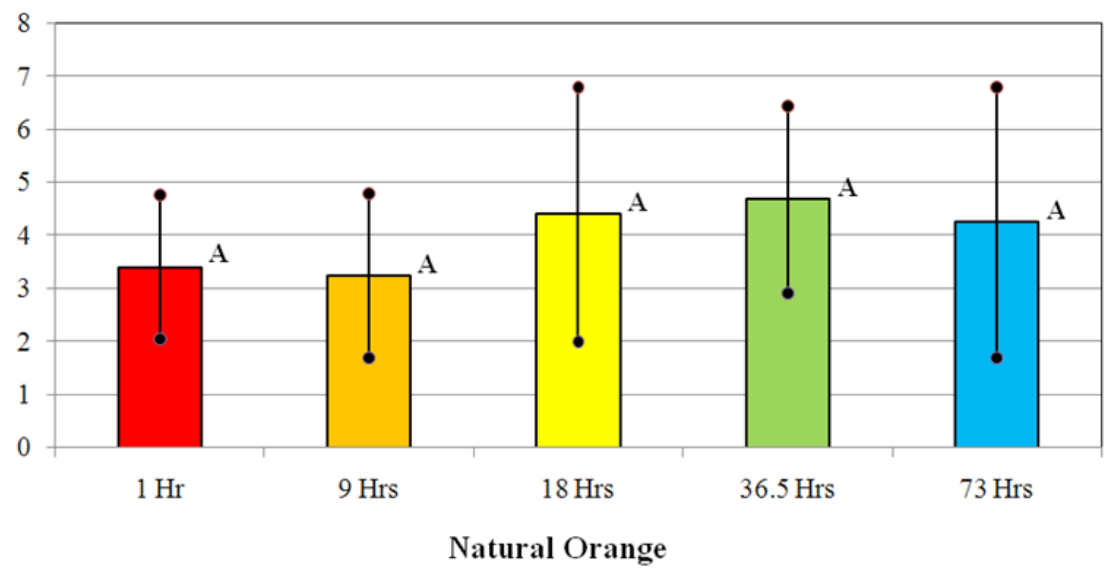

Figure (9) : Mean $\pm \mathrm{SD}$ and Duncan's multiple range test of color change $\Delta \mathrm{E}$ for comparison among immer-sion time intervals for natural orange 


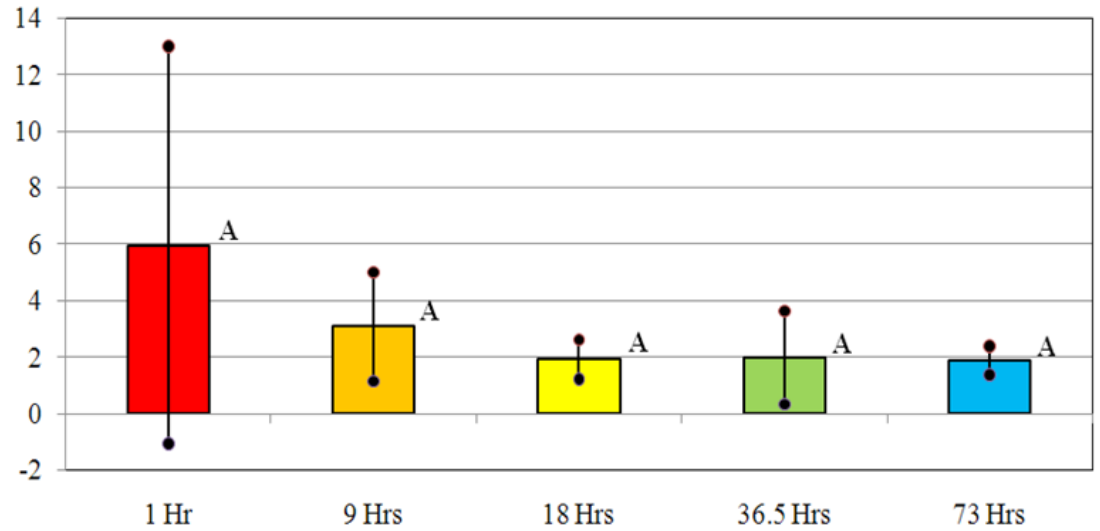

Figure (10) : Mean $\pm \mathrm{SD}$ and Duncan's multiple range test of color change $\Delta \mathrm{E}$ for comparison among immer-sion time intervals for cola

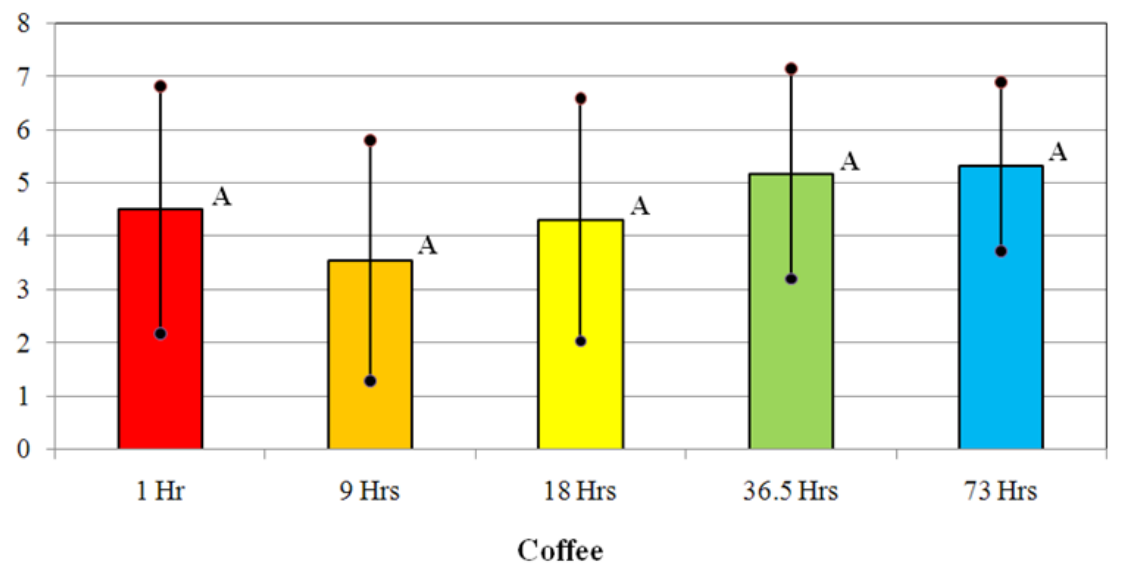

Figure (11) : Mean \pm SD and Duncan's multiple range test of color change $\Delta \mathrm{E}$ for comparison among immer-sion time intervals for coffee

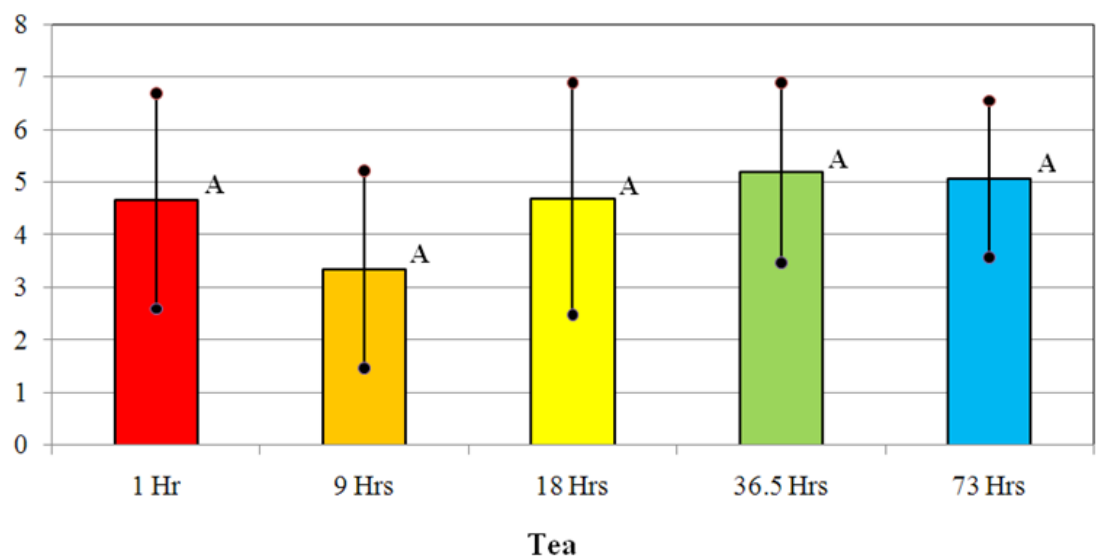

Figure (12) : Mean $\pm \mathrm{SD}$ and Duncan's multiple range test of color change $\Delta \mathrm{E}$ for comparison among immer-sion time intervals for tea

The one way analysis of variance (ANOVA) as shown in (Table 3) demonstrated that there was no significant difference among immersion time intervals for different types of beverages (Artificial orange, Distilled water, Zamzam water, Natural orange, Cola, Coffee, and Tea). 
Al-Noori AKH

Table (3) : Analysis of variance (ANOVA) for comparison of color change $\Delta \mathrm{E}$ among different types of beverage

\begin{tabular}{|c|c|c|c|c|c|c|}
\hline Time & SOV & SS & df & MS & F-value & p-value \\
\hline \multirow{3}{*}{$\begin{array}{c}\text { Artificial } \\
\text { Orange }\end{array}$} & Between Groups & 19.596 & 4 & 4.899 & \multirow{3}{*}{0.818} & \multirow{3}{*}{0.526} \\
\hline & Within Groups & 149.653 & 25 & 5.986 & & \\
\hline & Total & 169.249 & 29 & & & \\
\hline \multirow{3}{*}{$\begin{array}{l}\text { Distilled } \\
\text { Water }\end{array}$} & Between Groups & 17.346 & 4 & 4.337 & \multirow{2}{*}{1.513} & \multirow{2}{*}{0.229} \\
\hline & Within Groups & 71.634 & 25 & 2.865 & & \\
\hline & Total & 88.980 & 29 & & \multirow{4}{*}{1.296} & \multirow{4}{*}{0.298} \\
\hline \multirow{3}{*}{ Zamzam } & Between Groups & 16.832 & 4 & 4.208 & & \\
\hline & Within Groups & 81.167 & 25 & 3.247 & & \\
\hline & Total & 97.999 & 29 & & & \\
\hline \multirow{3}{*}{$\begin{array}{l}\text { Natural } \\
\text { Orange }\end{array}$} & Between Groups & 9.639 & 4 & 2.410 & \multirow{2}{*}{.613} & \multirow{2}{*}{0.657} \\
\hline & Within Groups & 98.318 & 25 & 3.933 & & \\
\hline & Total & 107.957 & 29 & & \multirow{4}{*}{1.622} & \multirow{4}{*}{0.200} \\
\hline \multirow{3}{*}{ Cola } & Between Groups & 73.344 & 4 & 18.336 & & \\
\hline & Within Groups & 282.618 & 25 & 11.305 & & \\
\hline & Total & 355.962 & 29 & & & \\
\hline \multirow{3}{*}{ Coffee } & Between Groups & 12.345 & 4 & 3.086 & \multirow{2}{*}{0.701} & \multirow{2}{*}{0.599} \\
\hline & Within Groups & 110.121 & 25 & 4.405 & & \\
\hline & Total & 122.466 & 29 & & \multirow{4}{*}{0.905} & \multirow{4}{*}{0.476} \\
\hline \multirow{3}{*}{ Tea } & Between Groups & 12.864 & 4 & 3.216 & & \\
\hline & Within Groups & 88.797 & 25 & 3.552 & & \\
\hline & Total & 101.661 & 29 & & & \\
\hline
\end{tabular}

SOV: Source of variance; SS: Sum of squares; MS: Mean square; df: Degree of freedom.

To measure color changes of highly impact resin, color change $(\Delta \mathrm{E})$ comparison between control group (without immersion) and other groups was shown in (Table 4). 
Table (4) : Color change $\Delta \mathrm{E}$ between control group and other beverage groups

\begin{tabular}{|c|c|c|c|}
\hline Time & SOV & SS & df \\
\hline \multirow{7}{*}{3 Hrs } & Artificial orange & 2.71150214 & Accepted \\
\hline & Distilled water & 2.21500900 & Accepted \\
\hline & Zamzam & 2.19777261 & Accepted \\
\hline & Natural orange & 3.40813775 & Accepted \\
\hline & Cola & 5.97688046 & Unaccepted \\
\hline & Coffee & 4.50446044 & Unaccepted \\
\hline & Tea & 4.65746991 & Unaccepted \\
\hline \multirow{7}{*}{9 Hrs } & Artificial orange & 2.48562833 & Accepted \\
\hline & Distilled water & 2.91202986 & Accepted \\
\hline & Zamzam & 4.21416931 & Unaccepted \\
\hline & Natural orange & 3.25185107 & Accepted \\
\hline & Cola & 3.09894761 & Accepted \\
\hline & Coffee & 3.54181787 & Accepted \\
\hline & Tea & 3.35132736 & Accepted \\
\hline \multirow{7}{*}{$18 \mathrm{Hrs}$} & Artificial orange & 4.39822064 & Unaccepted \\
\hline & Distilled water & 3.79544411 & Unaccepted \\
\hline & Zamzam & 3.94215295 & Unaccepted \\
\hline & Natural orange & 4.40538591 & Unaccepted \\
\hline & Cola & 1.93118071 & Accepted \\
\hline & Coffee & 4.31372002 & Unaccepted \\
\hline & Tea & 4.69303309 & Unaccepted \\
\hline \multirow{7}{*}{ 36.5 Hrs } & Artificial orange & 4.27528225 & Unaccepted \\
\hline & Distilled water & 4.35366683 & Unaccepted \\
\hline & Zamzam & 3.02090021 & Accepted \\
\hline & Natural orange & 4.68261597 & Unaccepted \\
\hline & Cola & 1.99500953 & Accepted \\
\hline & Coffee & 5.18020098 & Unaccepted \\
\hline & Tea & 5.18997560 & Unaccepted \\
\hline \multirow{7}{*}{$73 \mathrm{Hrs}$} & Artificial orange & 3.98207094 & Unaccepted \\
\hline & Distilled water & 3.90318768 & Unaccepted \\
\hline & Zamzam & 2.76049099 & Accepted \\
\hline & Natural orange & 4.25718138 & Unaccepted \\
\hline & Cola & 1.90373758 & Accepted \\
\hline & Coffee & 5.31700963 & Unaccepted \\
\hline & Tea & 5.07440180 & Unaccepted \\
\hline
\end{tabular}

$* \Delta \mathrm{E} \leq 3.7$ color change accepted in vitro

Artificial orange, Distilled water, and Natural orange groups showed an accepted $(\Delta \mathrm{E})$ values in vitro after $(3 \mathrm{hrs}$, and 9 hrs) of immersion and then converted to unaccepted $(\Delta \mathrm{E})$ values with increasing immersion time intervals $(18 \mathrm{hrs}, 36.5$ $\mathrm{hrs}$, and $73 \mathrm{hrs})$. The unaccepted $(\Delta \mathrm{E})$ values associated with increasing immersion time might due to increase water sorption which affect the degree of color change ${ }^{(16)}$ because water sorption develop some change in visual appearance ${ }^{(20)}$. The erosive activity of citric acid that present in Artificial orange juice $(\mathrm{pH}=2.66)$ and natural orange juice $(\mathrm{pH}=2.64)$ might play a role in increasing color change $(\Delta \mathrm{E})$ with increasing immersion time intervals ${ }^{(23,24)}$. 
Color change $(\Delta \mathrm{E})$ after immersion in coffee and tea showed unaccepted values at all immersion time intervals except at (9 hrs) of immersion were the values of $\Delta \mathrm{E}(3,54$ and 3,35$)$ for coffee and tea respectively. Generally, the unaccepted value of $\Delta \mathrm{E}$ after immersion in coffee and tea might due to the discoloration effect of coffee and tea beverages and accumulated layers of stain from coffee and tea ${ }^{(25)}$. The unaccepted values of color change $(\Delta \mathrm{E})$ associated with coffee was agreement with Rejab study ${ }^{(16)}$. The unaccepted values of color change $(\Delta \mathrm{E})$ associated with tea was agreement with AlTahho study ${ }^{(14)}$. The unaccepted values of $\Delta \mathrm{E}$ associated with coffee and tea were disagreement with the findings of imirzalioglu et al., ${ }^{(11)}$ who found that the color change $(\Delta \mathrm{E})$ of heat polymerized acrylic was accepts up to 30 th days of storage in coffee and tea. The difference of findings of present research from Imirzalioglu et al., was due to the different strategy of test work between the two researches. In the present research the control group (without immersion) after deflasking, finishing and polishing while the control group in imirzalioylu et al., research was immersed in saliva. In addition to the difference in immersion time between the two researches. The immersion time in the present research up to 24 months while in Imizalioglu et al., research only up to one month.

The values of color change $(\Delta \mathrm{E})$ after immersion in Cola were accepted for all immersion time intervals except at ( $3 \mathrm{hrs})$ of immersion where $\Delta \mathrm{E}$ was unaccepted, which might due to high acidity of Cola $(\mathrm{pH}=1.84)$ that cause solubility of resin resulting in unaccepted color change and with increasing the immersion time, absorption might take place. The equilibrium between two processes of solubility and absorption might decrease the color change $(\Delta \mathrm{E})$ within accepted values(13).

The values of color change $(\Delta \mathrm{E})$ after immersion in Zamzam water was accepted $(\Delta \mathrm{E})$ after (3 hrs) of immersion and became unaccepted after ( $9 \mathrm{hrs}$, and $18 \mathrm{hrs}$ ) of immersion and with increasing immersion time intervals to $(36.5 \mathrm{hrs}$, and 73 hrs) would return to accepted values. This behavior of color change associated with Zamzam water $(\mathrm{pH}=7.92)$ differ from that color change $(\Delta \mathrm{E})$ associated with distilled water $(\mathrm{pH}=7.0)$ might due to the presence of metals, cations and anions in composition of Zamzam water ${ }^{(22)}$.

\section{CONCLUSIONS}

Among beverages coffee and tea showed unaccepted value of $\Delta \mathrm{E}$ at all immersion time intervals except at ( $9 \mathrm{hrs})$ while cola showed an accepted values of $\Delta E$ except at ( $3 \mathrm{hrs}$ ) of immersion where $\Delta \mathrm{E}$ value was unaccepted.

\section{REFERENCES}

1. Anusavice K. Philips Science of Dental Materials. 10th Ed., Saunder Co; 1996.

2. Power J. And Wataha J. Dental Materials Properties and Manipulation. 9th ed., CV Mosby Com. St. Louis ; 2008.

3. Fernandes F, Orsi L, and Villabona. Effect of the peracetic acid and sodium hypochlorite on the color stability and surface roughness of the denture base acrylic resins polymerized by microwave and water bath methods. Gerodontol. Ogy. 2012: 17

4. Dhir G, David W, Virendra B, and Andrew D. Physical properties of denture base potentially resistant to Candida adhesion. J. Prosthodont. 2007 ; 16 : 465473.

5. Piresdesouza F, Panzeria H, Vieira M, Garcia L, and Consani S. Impact and fracture resistance of an experimental acrylic polymer with elastomer in different proportions. Mater Resea. 2009 ; 12: 415418.

6. Komal L, and Dipti S. An in vitro evaluatin of the flexural strength of heat polymerized polymethyle methacrylate denture resin reinforced with fiber. J. Ind. Prosthodont. Socie. $2011 ; 11: 215220$.

7. Arthur S, Fredreik C, and John C. Color stability of provisional prosthodontic materials. J. Prosthet. Dent. 2004 ; 91 : 447452.

8. Khan Z, Von Fraunhofer J, and Razavi $R$. the staining characteristics, transverse strength and microhardness of a visible light cured denture base material. J. Prosthet. Dent. 1987 ; $57: 384387$.

9. Chan K, Fuller J, and Hormati A. The ability of foods to stain two composite resins. J. Prosthet. Dent. 1980; 43: 542505.

10. Keyf F, and Etikan I. Evaluation of gloss changes of two denture acrylic resin materials in four different beverages. Dent. Mat. 2004 ; 20: 244251. 
11. Imirzalioglu P, Karacacr O, Yilmaz B, and Ozmen I. Color stability of denture acrylic resins and a soft lining material against. Tea, coffee, and nicotin. J. Prosthodont. 2010 ; 19: 118124.

12. Navarro W, Correa B, Borges C, Jorge J, Urban V, and Campanha N. Color stability of resins and nylon as denture base material in beverages. J. Prosthodont. 2011; 20: 631638.

13. Gupta R, Parkash H, Shah N, and Jain V. A spectrophotometric evaluation of color changes of various tooth colored veneering materials after exposure to commonly consumed beverages. J. Ind. Prosthod Soc., 2005 ; 5: 7278.

14. AlTahho O. Effect of different beverages and thermal cycling on some properties of flexible and modified heat cured denture base materials. 2011 M. Sc. Thesis, College of Dentistry, Mosul University.

15. 15. Hatim A, Taqa A, and Hasar R. Evaluation of the effect of curing techniques on color property of acrylic resins. AlRafidain Dent. J.2004; 4: 2833.

16. 16. Rejab L. Digital analysis of the color of the het cured acrylic resin (using scanner). AlRafidain Dent J. 2011 ; 11: 8895.

17. Khazal A. Evaluation the effect of chemical and irradiation disinfectants on some physical and mechanical properties of flexible denture base material. $2011 \mathrm{M}$. Sc. Thesis. College of Dentistry, Mosul University.

18. Alvin G, Delwin T, Shanglun K, and William M. Color accuracy of commercial digital camexas for use in dentistry. Dent. Mater J. 2006; 6: 553559.
Monica A, Pratheck S, and Sudhakar G.Shade matching in fixed prosthodontics using instrumental color measurement and computers. J. Ind. Prostho. Soc. 2007 ; 4: 179183.

19. Gariotek M, Sikorska E, Ferreira L, Costa A, Khmelinskii I, Krawczyk A, Sikorski M, and Koczorowski R. Color and luminescence stability of selected dental materials in vitro J. Prosthodont. $2012 ; 21: 112124$.

20. Al Aubodi S. New denture cleansers, A comparative study. $2007 \mathrm{MSc}$. Thesis Mosul University, college of dentistry.

21. Shamar B. Zamzam Water : concentration of trace elements and other characteristics. Chemosphere, 2012 ; 86: 600605.

22. Hamouda I. Effect of various beverages on hardness, roughness, and solubility of esthetic restorative materials J. Esthet and Restorat Dent. 2011 ; 23: 315322.

23. Scaramucci T, Hara A, Zero D, Ferreira S, Aoki I.,and Sobral M. Development of an orange juice surrogate for the study of dental erosion. Baz. Dent. J. 2011 ; 22: 473478 .

24. Awliya W, AlAlwani D, Gashmer E, and AlMandil $H$. the effect of commonly used types of coffee microhardness and color stability of resin based composite restoration. The Saudi Dent. J. 2010 ; 22: 177181.

25. AlAnsi S, Othman A, and AlTufail M. Bromate pollutant in ozonated bottled Zamzam wate from Saudi Arabia determined by LC/ICPMS. J. Environment. Science and Health. 2011 ; 46: 15291532. 